\title{
An Empirical Study Of Factors Influencing Gender Differences In Entrepreneurship
}

Kogilah Narayanasamy, Multimedia University, Melaka Campus, Malaysia

Devinaga Rasiah, Multimedia University, Melaka Campus, Malaysia

C J Jacobs, Multimedia University, Melaka Campus, Malaysia

\begin{abstract}
The paper examines the difference between male and female entrepreneurs and how those differences can be used towards the future development of entrepreneurship. The sample size consists of 21 entrepreneurs (10 male and 11 female). The interview method using questionnaires was used to obtain the information. There is sufficient evidence to indicate that characteristic differences were major factors found in the root of gender differences. Further, family background and social background were contributory factors in determining the differences of male and female entrepreneurs. Education level of both sexes also influenced the quality of entrepreneurs. Subsequently, Government policies also contributed towards gender differences in the entrepreneurship world. The different capabilities of male and female entrepreneur had significant impact on the entrepreneurship fraternity. Clearly, country and social roles too determine the success of entrepreneurial women.
\end{abstract}

Keywords: Entrepreneur; Characteristic Differences; Family Background; Social Background; Education Level; Government Policy; Capability Differences

\section{INTRODUCTION}

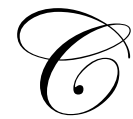

urrently, people are not only depending on employment but also exploring on initiating their own businesses. Studies have shown that there is growth among entrepreneurs in many Small and Medium Enterprises (SMEs), (Brindley, 2005). Small business Enterprises tend to have freedom of decision making, flexible working hours and also the profit motive.. However, it is not easy to become an entrepreneur. More so women must have some characteristics that will ensure them to become successful entrepreneurs. They have to be proactive and innovative and must have the ability to identify opportunities and risks (Mueller, 2007).

Today, the term "entrepreneur" is no longer dominated by males. In this $21^{\text {th }}$ century, the autonomy and power of woman have become more obvious and as clear. (Purdy 2005). Long time ago, women only played the role of mothers, confined to their homes and to take care of their household chores and children. Nowadays, women are not only independent but also have their autonomy in many aspects such as politics, education, socially and economically. They have the liberty of expressing their own ideas and displeasures on a variety of matters. There will always be discussions in comparison between men and women entrepreneurs (Brindley, 2005). Most people think that women are weaker than men in many factors. On the other hand, women are said to be more emotional when making decision and very risk aversive. Hence, women have to face more challenges and difficulties when setting up their own businesses. Confidence toward women as a successful entrepreneur can hardly be assured. (McClelland, Swail et al., 2005).

For many years gender-related barriers has hindered the economic potential of women as entrepreneurs. These barriers have had an adverse impact on enterprise development, productivity, and competitiveness. This represents a significant opportunity to unleash Malaysia's productive potential and to strengthen economic growth. 


\section{OBJECTIVE OF STUDY}

1. Find out whether the number of women entrepreneurs has increased over the years and if there are more women entrepreneurs.

2. To identify whether gender difference is a key factor for an organization, when they are looking for a manager.

3. To understand the different approaches that men and women take as entrepreneurs

4. To examine if there is a choice factor as to why men are preferred more then women as an entrepreneur.

5. To find out why men are more respected as entrepreneurs than women and the reasons for it.

6. Identify some of the challenges and barriers facing women entrepreneurs.

\section{RESEARCH PROBLEM}

While the contribution of women entrepreneur towards the economy of the society cannot be ignored, the rapid growth and progress of self-owned business due to the further economic improvement in the world further strengthens the increasing numbers of entrepreneur involved. Though, problems pertaining to gender differences are on the rise, female are certainly no-longer out of the race.

\section{LITERATURE REVIEW}

\section{Characteristics Differences}

Despite its intrinsic interest and importance, little is known precisely why there is less female than male entrepreneurship (Parker, 2004).Thus, women are believed to be more nurturing is more appropriate to assign as a nurse rather than masculine men (Mueller, 2007). Different forms and degrees of masculine and feminine behaviors adopted by men and women may certainly affect the ways in which businesses are managed (Marlow \& Patton, 2005). In addition, gender differences may influence the styles and exercise of power in an organization (Rajan \& Venkat, 2002). In this study, findings suggest that combination of gender and personality can affect power and influence.

In recent studies, researchers have been discussing about how self-confidence may motivate some individuals to become entrepreneurs and may not motivate others. This concept proposes that self-confidence maybe included in career development and career choice for either men or women. Furthermore, it also believed that selfconfidence plays an important role in the new venture process (Mueller, 2007). In the article of Brindley (2005), she stated "Perceptions may be influenced by the self-confidence levels of the individuals involved in the entrepreneurial venture. If an individual is confident the situation or decision maybe seen as less risky but if the individual lacks confidence then they may perceive more barriers and anticipate the decision to be more risky." Which means it is not affected by gender; perception and performance differ by self-confidence, not gender.

The study of Wagner (2007) also documented significant differences in risk aversion between men and women entrepreneurs although they exhibited similar traits. Based on Wagner (2007) analysis, findings showed that women have higher fear of failure than men. Women are less likely to take up risk than men. The main challenges facing these women were both personal and business related. There was also conflict between the roles traditionally assigned to Asian women and the need to succeed in the marketplace (Dhaliwal \& Kangis, 2006). Women perceived much lower financial risk than men, which indirectly affected the success they attained (Boohene, Sheridan \& Kotey, 2008).

Aggressiveness bordering on abrasiveness, hard-driving, lack of sensitivity to the existing organizational culture is normally associated to men while caring, sensitive, and nurturing attributes are associated with women (Klenke, 2003). In some countries, a male is encouraged to be aggressive and to display "machismo" where these qualities may build up their self-esteem and confidence (Bortey \& Dodoo, n.d.). With this, the values of males in these societies reflect assertiveness, risk taking, independence, innovativeness and achievement orientation. (Boohene, Sheridan \& Kotey, 2008) On the other hand, women were totally the opposite of these values. They have to bear the primary responsibility for child-nurturing, cooking, washing and collecting fuel-wood and water 
(Boohene et al, 2005; Nikoi, 1993). In this case cited in Canada Boohene, Sheridan and Kotey (2008), indicated that both women and men put up different emphases on various process. When compared to men, women started smaller business and on an average had less managerial experience. These had impacts on various other aspects of the business processes and performances.

There are other characteristics between men and women such as women valued job security more than men and men. Men saw themselves as confident, as loved challenges and having the natural skills to manage than women. Malach-Pines \& Schwartz, (2007) indicated that women are found to use more calming coping than men; men are found to be more motivated by status than women. Women tend to use social support more frequently and to a greater extent than men.

However, there are contradictions to the statement above where characteristics do not make differences. In the analysis of Marlow and Patton (2005), they also argued that not every man will pursue characteristics of masculine while not every woman will pursues characteristics of feminity. This is supported by Bird and Brush (2002) where they stated that there are cases where organizations initiated by men do have attributes of feminity while organizations initiated by women do have attributes of masculinity as well. Mueller (2007) suggested that one's intention to start up a new business is mostly based on the outcome that most probably will occur. Furthermore, the most concerned question is about whether the new venture ends up being failure. In Mueller's (2007) studies, he further discusses that gender difference does not affect the entrepreneur self-confidence. But some debated this claim, it is believed that the gender difference in risk aversion is not the same, women used to be more concern about the success of a new venture.

\section{Family Background}

Justo and Coduras (2006) stated that in their study, they examined to an extent those female and male entrepreneurs where very different in the way they perceived and looked at success. Some results indicated that there were a small number of similarities between men and women entrepreneurs. The most gender-based differences were towards family status (Justo \& Coduras, 2006). Assuming that women entrepreneurs are a homogeneous group, they found that family values, especially parental status, played and important role in shaping fundamentally different perceptions of entrepreneurial success amongst different types of women entrepreneurs. In particular, women entrepreneurs with dependent children placed more emphasis on independence as a measure of success than other types of entrepreneurs.

\section{Social Background}

Female entrepreneurs used less initial capital to start up their business than do male entrepreneurs. The traditional explanation for this disparity is that women do not have as much contacts as men to venture funding. But it may also be that women do not seek out venture capital to the same degree as men, for several reasons. Perhaps they are apprehensive towards encountering bias against women in the allocation of start-up financing. Pines \& Schwartz, (2007), indicated that another possible explanation is that female entrepreneurial activity are less capitalintensive than male activity because of the kinds of business sectors that attract female entrepreneurs such as, consumer retail, health and beauty services. In other words, female entrepreneurs go into business ventures which are less capital intensive than do male entrepreneurs.

In the study of Istanbul (2004), women entrepreneurs help develop the economy. They are able to create job for themselves and also for others. Mueller's (2008) in a study indicated that women's entrepreneurship depended on both the situation and the role of women in the same society. We are therefore dealing with factors that affect the gender system and the factors that affect the situation. There have been some obstacles to women's entrepreneurship such as level of education, gendering of entrepreneurship, weak social status, and demands on time and access to finance. One study showed that Asian women are not strongly represented in self-employment in the developing country. This is not the case in Malaysia as the government has now implemented several programs to help women attain entrepreneurship. 
Wiebe and Frank (2003) found that social learning differences have a strong impact on shaping preference for an entrepreneurial career. For women, they are actually had stronger education and training aspirations for entrepreneurship than men. Providing informal as well as formal learning experiences for women would be important to help them obtain the necessary education and training to be successful as entrepreneurs. Besides, women believe entrepreneurship is not a viable career option. They need specific opportunities to become an entrepreneurial to develop the feeling of competency and strong expectations for success to complement their aspiration for venture creation and management.

However, research has indicated that women in lesser developed countries may rely on social networks as substitutes for formal legal contracts more than men in those same countries (Woldie \& Adersua, 2004). For example, a study of female entrepreneurs in Vietnam concludes that because government institutions were less helpful to female entrepreneurs, many of the women depended on informal social networks of government officials to support and approve their projects. Across the country-specific studies of female entrepreneurs surveyed, the most frequently mentioned success factor is support from friends and family (including domestic help). Several other countries such as, in Oman, Cyprus, and Hungary, explore women's views that familial networks were important to their entrepreneurial success (Levent, Masurel et al., 2003). Research findings indicate that entrepreneurs' use of social networks raises some important questions. Perhaps these answers could help guide programs aimed at increasing female entrepreneurship. One researcher, for example, suggests that women entrepreneurs' networks are smaller and more geographically concentrated than are men.

\section{Government Policy}

Female small business owners use less initial capital at start-up than male business owners. In total, men used three times more start-up capital than women, and this was related positively and significantly to current value of capital assets, sales turnover, and total number of employees (Jarvis, 2000). Gaining access to bank finance for many new starters is problematic in terms of access and cost but again, it can be argued that women will have to overcome greater hurdles than their male counterparts if they chose this particular pathway. It has already been argued that women are less likely to get access to security and collaterals to strengthen loan applications. The current government policy, aims to encourage more women into self employment (SBS, 2005) and this has been reflected by banks, who claim to look favorably upon applications from self-employed women (Barclays, 2000). The outcomes of such policies evaluated banking policies but not on banking decisions alone. The also reflect on the various aspects of different sectors and employment which represent challenges beyond the scope of the banking community.

\section{Education}

In Developing Countries, girls have been reported as having lower education levels than boys in areas related to math, finance, decision making, and problem solving (Marlino \& Wilson, 2003). Studies have indicated that with adults, the gender differences are primarily observed in domains that are stereotypically associated with "male" skills, including business/entrepreneurial careers.

In order to effectively and efficiently address this topic, policy makers need more knowledge about women entrepreneurs. Based on existing studies, we explore why women's entrepreneurs are different from men's entrepreneurship both in quantity and form. The argument is made for an Austrian-economic perspective (Shane \& Venkataraman, 2000; Venkataraman, 1997). Entrepreneurship plays an important role in the development and creation of knowledge management into future goods and services through industrial and innovations.

Another fundamental feature of entrepreneurs is the portioning of knowledge among individuals, such that no two individuals share the same knowledge or information about the economy. The important essences of this knowledge are diffused into the economy but not at everyone's disposal. Hence, only a few know about a particular opportunity. This knowledge is idiosyncratic because it is acquired through each individual's own experience and knowledge which include occupation, on-the-job routines, social relationships and daily life (Acs, 2002). Further to this, in most economies, there is a large difference in education between men and women .Women are in general underrepresented in science and technology related fields and overrepresented in the humanities. This means that 
women will be less present in some business sectors where a formal education in science and technology is required and overrepresented in other fields.

In a study conducted by Bandura's (1992) found that there was a gender differences in capability, where there was significant evidence to suggest that women are more likely than men to limit their career aspirations and interests because they believe that they lack the necessary capabilities (Bandura, 1992). Recent studies have showed evidence that girls are moving toward academic parity in subjects such as math and science, but still shunning careers in these fields, Bandura suggests that these perceived inefficacies, as well as other sociostructural encumbrances, weigh more heavily with girls than does background preparation when considering careers (Bandura et al., 2001).

Table 1. Prevalence Rates of Entrepreneurial Activity across Countries by Gender 2005

\begin{tabular}{|c|c|c|c|c|c|c|}
\hline & \multicolumn{2}{|c|}{ Early stage entrepreneur stage } & \multicolumn{2}{|c|}{ Established business owner } & \multicolumn{2}{|c|}{ Overall business owners } \\
\hline & Male & Female & Male & Female & Male & Female \\
\hline Australia & $11.62 \%$ & $7.55 \%$ & $12.08 \%$ & $7.09 \%$ & $23.70 \%$ & $14.65 \%$ \\
\hline Austria & $9.68 \%$ & $3.66 \%$ & $5.10 \%$ & $2.58 \%$ & $14.78 \%$ & $6.23 \%$ \\
\hline Belgium & $1.39 \%$ & $2.42 \%$ & $7.23 \%$ & $4.03 \%$ & $8.62 \%$ & $6.46 \%$ \\
\hline Brazil & $15.24 \%$ & $10.83 \%$ & $13.33 \%$ & $7.00 \%$ & $28.58 \%$ & $17.84 \%$ \\
\hline Canada & $14.21 \%$ & $5.56 \%$ & $9.72 \%$ & $5.09 \%$ & $23.93 \%$ & $10.65 \%$ \\
\hline Chile & $14.17 \%$ & $8.21 \%$ & $4.82 \%$ & $2.76 \%$ & $18.98 \%$ & $10.97 \%$ \\
\hline China & $11.82 \%$ & $11.60 \%$ & $16.06 \%$ & $10.27 \%$ & $27.88 \%$ & $21.87 \%$ \\
\hline Croatia & $5.43 \%$ & $2.58 \%$ & $4.74 \%$ & $2.61 \%$ & $10.17 \%$ & $5.19 \%$ \\
\hline Denmark & $5.08 \%$ & $3.09 \%$ & $6.56 \%$ & $2.12 \%$ & $11.64 \%$ & $5.21 \%$ \\
\hline Finland & $7.17 \%$ & $4.41 \%$ & $12.43 \%$ & $4.73 \%$ & $19.59 \%$ & $9.14 \%$ \\
\hline France & $6.40 \%$ & $3.33 \%$ & $2.76 \%$ & $1.79 \%$ & $9.16 \%$ & $5.11 \%$ \\
\hline Germany & $8.67 \%$ & $3.82 \%$ & $5.99 \%$ & $2.35 \%$ & $14.66 \%$ & $6.18 \%$ \\
\hline Greece & $7.40 \%$ & $3.37 \%$ & $11.36 \%$ & $9.63 \%$ & $18.76 \%$ & $13.00 \%$ \\
\hline Hungary & $6.58 \%$ & $2.39 \%$ & $2.08 \%$ & $1.95 \%$ & $8.66 \%$ & $4.34 \%$ \\
\hline Iceland & $13.11 \%$ & $6.40 \%$ & $9.05 \%$ & $5.48 \%$ & $22.16 \%$ & $11.88 \%$ \\
\hline Ireland & $9.56 \%$ & $5.48 \%$ & $12.26 \%$ & $3.88 \%$ & $21.81 \%$ & $9.35 \%$ \\
\hline Italy & $6.90 \%$ & $3.70 \%$ & $9.17 \%$ & $3.64 \%$ & $16.07 \%$ & $7.34 \%$ \\
\hline Jamaica & $21.65 \%$ & $15.69 \%$ & $9.57 \%$ & $9.49 \%$ & $31.22 \%$ & $25.18 \%$ \\
\hline Japan & $3.20 \%$ & $1.20 \%$ & $7.67 \%$ & $3.11 \%$ & $10.87 \%$ & $4.31 \%$ \\
\hline Latvia & $7.28 \%$ & $5.02 \%$ & $6.57 \%$ & $3.60 \%$ & $13.85 \%$ & $8.62 \%$ \\
\hline Mexico & $5.88 \%$ & $4.55 \%$ & $3.11 \%$ & $0.77 \%$ & $8.99 \%$ & $5.32 \%$ \\
\hline Netherlands & $3.20 \%$ & $2.11 \%$ & $7.35 \%$ & $3.94 \%$ & $10.55 \%$ & $6.05 \%$ \\
\hline N Zealand & $15.73 \%$ & $13.75 \%$ & $13.83 \%$ & $8.03 \%$ & $29.56 \%$ & $21.77 \%$ \\
\hline Norway & $5.52 \%$ & $4.47 \%$ & $10.10 \%$ & $4.38 \%$ & $15.62 \%$ & $8.85 \%$ \\
\hline Singapore & $8.47 \%$ & $5.04 \%$ & $7.49 \%$ & $2.15 \%$ & $15.95 \%$ & $7.19 \%$ \\
\hline Slovinia & $9.78 \%$ & $2.92 \%$ & $8.74 \%$ & $3.78 \%$ & $18.52 \%$ & $6.70 \%$ \\
\hline South Africa & $3.91 \%$ & $4.49 \%$ & $1.63 \%$ & $1.00 \%$ & $15.54 \%$ & $5.49 \%$ \\
\hline Spain & $6.92 \%$ & $4.15 \%$ & $8.75 \%$ & $6.68 \%$ & $15.67 \%$ & $10.83 \%$ \\
\hline Sweden & $5.79 \%$ & $2.99 \%$ & $8.68 \%$ & $3.91 \%$ & $14.48 \%$ & $6.90 \%$ \\
\hline Switzerland & $7.38 \%$ & $4.89 \%$ & $11.86 \%$ & $7.59 \%$ & $19.24 \%$ & $12.47 \%$ \\
\hline Thailand & $18.37 \%$ & $19.33 \%$ & $15.09 \%$ & $13.15 \%$ & $33.46 \%$ & $32.49 \%$ \\
\hline U Kingdom & $6.17 \%$ & $3.74 \%$ & $8.06 \%$ & $2.08 \%$ & $14.24 \%$ & $5.82 \%$ \\
\hline United States & $14.15 \%$ & $9.65 \%$ & $6.01 \%$ & $3.35 \%$ & $20.15 \%$ & $13.00 \%$ \\
\hline Venezuela & $22.20 \%$ & $23.86 \%$ & $10.93 \%$ & $6.25 \%$ & $33.13 \%$ & $30.12 \%$ \\
\hline
\end{tabular}

In several studies conducted by Chen et al., (1998); Chowdhury \& Endres, (2005); Gatewood, Shaver, Powers, \& Gartner, (2002); Kourilsky \& Walstad, (1998), indicated that there is little specific research examining the interactions between entrepreneurial self-efficacy, entrepreneurial intentions, and gender, preliminary evidence showed that women have both lower entrepreneurial self-efficacy and lower entrepreneurial intentions. Additionally, 
as suggested by the research of Bandura et al. (2001), women may be more strongly influenced then men by any perceived skill deficiencies in the entrepreneurial realm. In one study, Kourilsky and Walstad (1998) compared perceptions of capability with actual entrepreneurial skills, and showed that while skill levels of boys and girls were comparable, girls who did not have those skills.

Research by Kickul and others (2004) supported these findings were having a direct relationship between self-efficacy and intentions in adolescent girls, with entrepreneurial aspirations. There is evidence that self-efficacy among women and entrepreneurial intentions which exist well outside the cultural and political boundaries of the United States. The most recent Global Entrepreneurship Monitor study reported that among adult women, i.e., women professed lower levels of confidence and preparedness in their ability to succeed as entrepreneurs. As suggested earlier, the perception of having the needed skills is shown to be a dominant variable that has an effect independent of other contextual variables (Minniti et al., 2005). Entrepreneurial activity varies by country across the world economy.

\section{RESEARCH METHODOLOGY}

According to Marlow and Patton (2005), characteristics differences between male and female may affect the management of the business among entrepreneurs. Based on the literature we found, researches stated that the characteristics differences can be in term of confidence level (Brindley, 2005; Malach-Pines \& Schwartz, 2007; Mueller, 2007), motivation level and independence level (Boohene, Sheridan \& Kotey, 2008), risk-taking (Wagner, 2007; Boohene, Sheridan \& Kotey, 2008), as well as physical characteristics (Klenke, 2003; Malach-Pines \& Schwartz, 2007).

Family background does affect the gender differences among entrepreneurs (Justo \& Coduras, 2006). It is very important whether or not family provided their support. In addition, social perception on entrepreneurs does affect gender differences. Females often get different treatment, as compared to male in the same society (Mueller's, 2008) such as financial support by the society (Pines \& Schwartz, 2007).

Some government policies may encourage females to get involved in entrepreneurship (Barclays, 2000; SBS, 2005).Different capabilities of female and male do affect their intention in entrepreneurship (Kickul et al., 2004; Minniti et al., 2005). With all the relevant literatures reviewed, a theoretical framework was developed for further data collection, analysis and discussions.

\section{THEORETICAL FRAMEWORK}

\begin{tabular}{|l|l|}
\hline \multicolumn{1}{|c|}{ Independent Variable } \\
Characteristics Differences \\
Family Background \\
Social Background \\
Government Policy \\
Education \\
Capability
\end{tabular}$\quad$\begin{tabular}{r|}
$\frac{\text { Dependent Variable }}{\text { Gender Differences in }}$ \\
Entrepreneurship
\end{tabular}

Figure 1: Factors that influence Gender Differences in Entrepreneurship

\section{Sources of Data and Data Collection}

The source of data was primary source collected by conducting individuals' interviews. Primary sources are original sources from which the researcher directly collects data that have not been previously collected. Primary data are first hand information collected through various sources and methods (Sekaran, 2003). According to BusinessDictionary.com (2009), interview is defined as "A somewhat formal discussion between two parties in which information is exchanged. For a business looking to fill an open job position, an employee might interview potential candidates to gain a better understanding of their backgrounds, qualifications and skills. 
Individual interviews were conducted with 21 interviewees who are the entrepreneurs that have their own business on hand. Those individual entrepreneurs are from different states in Malaysia. Respondents are found based on quota sampling. Quota sampling ensures that certain groups are adequately represented in the study through the assignment of a quota (Sekaran, 2003). From the 21 interviewees, 10 are males and 11 are females. This is to make sure that the responses the study gained will be no bias due to responses from different gender. The interviewees chosen are based on convenience. Not every entrepreneur in Malaysia has equal chance of being chosen. The interviewees are volunteers. Researchers of this study used their own networks to get the interviewees such as friends, family and relatives.

Table 2 Adult Literacy Rate, selected regions, 1995-2005

\begin{tabular}{|l|c|c|}
\hline \multicolumn{1}{|c|}{ Regions } & Female Rate & $\begin{array}{c}\text { Ratio of Female to } \\
\text { Male Rate 1995-2005 }\end{array}$ \\
\hline Arab States & 59.4 & 0.88 \\
\hline East Asia and the Pacific & 8.67 & 0.99 \\
\hline Latin America and the Caribbean & 89.7 & 1.01 \\
\hline South Asia & 47.4 & 0.81 \\
\hline Sub-Saharan Africa & 51.2 & 0.84 \\
\hline Central and Eastern Europe \& CIS & 98.7 & 1 \\
\hline World & 72.7 & 0.92 \\
\hline
\end{tabular}

Source: Human Development Report 2007/2008, Table 30

\section{ANALYSIS AND DISCUSSION}

\section{Characteristics Differences}

According to the respondents, there is a wide range of characteristics that should be pursued by entrepreneurs. Ability to take risk (Yen, Teo, Piong, Koh \& Addy), honest (Teo, Piong, Fairuz \& Addy), creativity (Yap, Khoo \& Koh), hardworking (Rawrays Co., Teow, Yap, Elaine \& Koh), ability to make good decision (Teow, Khoo, Teo, Piong \& Addy), motivativation and dedication (Diana, Ling \& Koh), leadership qualities (Yen, Poziyah, Fairuz \& Addy), willingness to learn (Yen \& Lee), far-sightedness (Lee \& Yap), as well as never give up (Ling \& Elaine) are some of the characteristics that the respondents taught, that they should have pursued in becoming entrepreneurs. Despite that, many respondents stated that their interest and understanding in a particular business of individuals is also very important for the success of their business.

The majority of the people stated that they had confidence at the initial stage to build up their business. Some of them said that this is because their family had set up the business for a certain period and the business were running well, and the customer base was strong. Others indicated that they had already had proper planning before they started their business. Minority stated that they do not have confidence in setting up a business because they themselves lack the confident (Ling) and scared that the business might not produce the expected results (Piong \& Addy). In term of physical characteristics inborn in female and male, almost all of the respondents agreed that there were no physical differences. However, some of the businesses were not suitable for females because of the nature of the business which required women to carry and moving heavy boxes and working around the clock such as selling local and import fruits (Diana) and some might was not suitable for males, such as baby sitting and child care because it was more orientated toward women. Lee had a different perception of everything should be, she said that only 50 percent of the success of the business was due to family support and the other 50 percent was all negative feedback which she got from men and women because she was she was involved in business that was dominated by male.

In terms of confidence level, most people taught that there were no differences between male and female entrepreneurs. They taught it depended on whether they had the desire and motivation to be successful. Some of them stated that male were more confident than female because the male would take more risk than women (Khoo). Females were reluctant to use their capital (Koh) and had restrictions to go far with their business such as they were not allowed to go to Night clubs like men did and talk business strategies for long hours like men (Khoo). Some also 
stated that females were skeptical to go into business because they were scared of losing all their money (Elaine) and some very calculative (Koh) and did not want to take on the risk.

In terms motivational level, most of them agreed that there was no difference between men and women. However, there were some controversy issues and some women indicated that most of the time men had more accessible to resources (Rawrays Co.) and were more motivated than females. Male were more ambitious (Khoo) while "females were emotionally unstable due to their physical nature (i.e. periods) and were less motivated when confronted with challenges" (Koh). There was a special response from (Zainorin) whereby she stated that females were more motivated only because they were determined to make their business a success to show to their own family and to the community that women also become successful entrepreneurs.

Most of them responded that there was no difference among female and male entrepreneurs in term of independence level. However, the disagreement stated that male would take up more risk and any risk as compared to female, only because they were financially stable, they had proper planning and experience (Elaine). Koh indicated that he supported this fact and stated that about 90 percent of the successful entrepreneurs were males, females needed security and guidance from while most males were independent (Yen). This is shown in the case of Teo and Piong as well where Teo was a male entrepreneur who thinks that he can handle his business by himself while Piong, a female entrepreneur who believes that she still had to seek help from those who had experience. However, this argument was rejected by Khoo, where she had given an example of her female friend who was with her family working alone in Indonesia. Others voices supported Khoo's statement where they said it is depended on individuals and not differences in gender.

Most of the people under study agreed that the male would take more risk as compared to their female counterparts. Females tend to consider more variables when they think it is risky. But Yen thinks that risk averse should be related to experience and characteristics of the individual, and not gender. As stated by Elaine, female tend to have the thinking "men should take up the responsibility" and think for the future (i.e. for family) while building their own business. In term of the desired achievement, most respondents taught that there was no difference between male and female, it only depended on the individual. Some female entrepreneurs provided reason where it was their hard work that contributed in achieving their goal (Elaine \& Piong). This statement was supported by Fairuz, he said that although females may have different motives to become self-employed as compared to males, that it was their extra-ordinary motives which will always will be the challenge for their survival and success of the enterprise. Therefore it is important for them to achieve it. On the other hand, Khoo and Koh taught that males will have an inner desire to achieve their goals. This is because males have higher ambition than females (Khoo).

Males are perceived to be braver, more ambitious, and more aggressive, more open minded, able to solve problem, had good management skills, long vision and always are willingly to learn from mistakes (Poziyah, Ling, Khoo, Koh \& Addy). These characteristics can help the males to perform better in term of getting new business, better management and development of the business. In addition, Teo and Piong argued about the emotional stability among male. Piong thinks males are emotional unstable while Teo do agree that emotional stability is important for males to succeed. Conversely, females are said to be hardworking (Poziyah, Ling \& Elaine), stable and steady (Khoo \& Rawrays Co.), very details, caring and friendly (Koh, Yap \& Yen) as well as able to focus intensely (Fairuz). These characteristics can help females to lower down the risks and establish good relationship with customers.

\section{Family Background}

When the respondents decided to start up their own business, all of them did receive support and encouragement from their family. Besides this they also received mental support from their family members, some of the respondents did receive financial support from their family, for instance borrowing money as startup capital from their family members (Piong \& Teh).

Regarding on how female entrepreneurs keep their balance between work and family. The response received showed that those who believed that the female entrepreneurs were able to balance their work were competitively on-par with those who thought of females not being able to balance work and family well. To this 
effect women were believed to have good time management skills (Yap \& Elaine). This was further supported by Fairuz who stated women do employ flexible work practices, such as preparing a room at workplace for child care (Lim). This is shown in the case of Poziyah and Yen where Poziyah as a female entrepreneur did have a well balanced life between family and work. However, this argument was rejected by Teow and Ganesan, who were new entrepreneurs in the scene, indicated that one must put more effort into her business to keep it running. This was supported by Diana, a married woman who had undergone through some hard times indicated that one must balance time between their family and their work, but where single woman had an added advantages.

All of the respondents have agreed on giving full support to their children if their children planed to startup their own business in the future. However, young entrepreneurs may have needed to convince their parents before receiving their support (Lee, Rawrays Co. \& Yen). Both male and female respondents believed that there are no relationships in term of entrepreneur's gender and their family background. "Gender doesn't make a difference" (Elaine). Supported by Koh and Khoo, who highlighted that what really will influence male and female to do business is their interest and determination in becoming an entrepreneur.

\section{Social Background}

Some of the respondents have faced social draw backs from their customers, competitors and suppliers (Ganesan, Fairuz \& Lee). Meanwhile, the others did not experienc such incident when they newly ventured into business. "To be frankly, they (supplier and competitor) wish to maintain a good relationship with me, this they won't voice out their opinion directly" (Khoo).

The majority do believed that social perspective and regional culture are important determinants to inspire one to become entrepreneurs. "I believe it does play a significant role to a certain extend as we need the support and recognition from the society and public in order to build a successful entrepreneurship" (Lee). However, despite most of the respondents reply Ling believes that entrepreneurs still have the right to choose the path they would like to pursue.

Table 3 Source: Malaysia Dept of Statistics 1980, 1990, 2000, 2004

\begin{tabular}{|c|c|c|}
\hline & \multicolumn{2}{|c|}{ Labour for participation rate by sex, Malaysia 1980- 2006 } \\
\hline Year & Female & Male \\
\hline 1980 & 44 & 85.9 \\
\hline 1990 & 47.8 & 85.3 \\
\hline 2000 & 47.2 & 83 \\
\hline 2006 & 45.8 & 79.9 \\
\hline
\end{tabular}

Regarding the issue of discrimination toward the female entrepreneurs, the respondents mainly believed there was some discrimination that female entrepreneurs might face, such as job differences, cultural (Teow \& Yen) and traditional factors (Koh \& Rawrays Co.). Meanwhile, there are claims that currently indicate that we have less gender discrimination which result in most of the female entrepreneurs having a successful business (Elaine \& Teo).

Further on the discussion, some respondents preferred to deal with the opposite gender, while other respondents believed that it was much easier to deal with same gender (Ganesan \& Poziyah). However, most of the respondents had a different view on business partners characteristic and experience rather than gender differences (Addy \& Teh). Regarding the issue on where female entrepreneurs may have faced a hard time in getting others to accept their ideas, the results showed that female entrepreneurs had no problems in presenting their ideas and on contrary were on-par with males. "It's always hard to convince others especially when you are young and inexperienced" (Lee). "People used to reject my ideas simply because I was a female" (Toh). 


\section{Government Policy}

The majority of the respondents believed that female entrepreneurs won't face many barriers in relation to their gender characterizations when seeking appropriate and adequate source of funding for their ventures. According to Addy and Poziyah, the current government policies have no gender discrimination. Furthermore, most respondent believed that bankers looked more into entrepreneurs' proposal plans and their companies' background rather than looking at what gender they were. (Elaine, Khoo \& Koh). This statement is supported by Piong, who have successfully applied for her loan s without any problems.

In terms of the amount of start-up capital, the responses from the respondents believed that woman entrepreneurs require lesser start-up capital compared to the males are equivalent to those who believed there are no relationship between the amounts of start-up capital.. According to Diana and Koh, female entrepreneurs tend to have lesser start-up capital, because their risk adverse level where women tends to avoid taking risk is supported by Lee and Khoo who believed female are more careful when money is concerned.

Lastly, the majority of both genders were not aware start-up for Malaysian entrepreneurs' schemes that existed in Malaysia for developing entrepreneurs particularly, female entrepreneurs. Lack of promotion is believed to be one of the main reasons for the lack of awareness of the schemes, "Not often though, but sometimes they do advertise those scheme" (Khoo \& Teow).

\section{Education}

According to the some respondents, they had a different view on the importance of education. Most of them agreed that education was important for entrepreneurs (Addy, Koh, Elaine, Jakel Trading, Khoo, Piong, Poziyah, HiBoss, Yen, Lee, Yap, Diana, Teow, Zainorin, \& Rawrays Co.). Through education, people can procure information of doing business thus avoiding being cheated by others (Addy, Rawrays Co. \& Teow), having enriched ideas in doing business (Khoo), and having a head start to compete with others (Piong \& Diana). If one had higher education, people will not look down on you and you can distinguish right from wrong (Yap). In contrast to this a few of them stated that experience was important as well as education and also initiative. (Ling, Elaine, Teo, Zainorin \& Teh) although the experiences took a longer time to be achieved (Zainorin). They said that some professional need experiences rather than education (Eddie, Lim \& Zainorin). Having initiative, coming from a disciplined upbringing and socializing were important traits in entrepreneurship (Ling, Elaine \& Teh). Some of them thought that the education system in Malaysia did not promote entrepreneurship, as the education system gave only basic information and skills of entrepreneurship (Addy, Ling, Koh, Elaine, Teo, Eddie, Lim, Teow, Rawrays Co., \& Teh). Besides, the entrepreneurship course also helped a lot in business management and had a sharp foresight into business marketing (Piong). Moreover, in the Ninth Malaysia Plan, the government had promoted Small and Medium sized Entrepreneurs SMEs (Yen). Although Malaysian education system promotes entrepreneurship, there is still room for improvement (Lee).

Most of the entrepreneurs said that obtaining education and training was very important for men and women (Koh, Elaine, Jakel Trading, Khoo, Piong, Poziyah, Hi-Boss, Yen, Lee, Eddie \& Lim, Yap, Teow). Education helped them to update their knowledge as well (Khoo). Besides, personality, capability was also important to entrepreneurs (Piong). From this, we can see that education was quite important for male and female entrepreneur to run their business smoothly. However, few of them agreed that the females were relying on education but male were not (Teo). Some job required more experience rather than education (Elaine). Furthermore, women will be respected by others when they had higher education (Rawrays Co.).

\section{Endurances}

There are two different views in handling stress among female. Women may be more vulnerable to stress as women are more sensitive, do not know how to control their emotion in some situations and conditions (Poziyah, Ganesan, Diana, Fairuz, Zainorin, Rawrays Co., Koh, \& Elaine). In contrast, some of them felt that women could handle stress well as men; they were seen as were calm, careful and rational (Teo, Piong, Khoo, Teh, Ling, Teow, Eddie, Kue Lan, Yap \& Yen). In some cases, women could handle stress better and endure stress more than men. 
They would not easily break down by stress (Khoo).In a few circumstances, female entrepreneur excelled better than men. Female entrepreneurs helped a lot in marketing and they were good in management (Addy \& Zainorin). However, a few of them preferred male entrepreneurs. Male entrepreneurs tended to be less emotional, had the ability in handle more stressful matters. However, most of them said that they would choose both based on their capability on the kind of business they did which was suitable to them (Yen, Eddie, Kue Lan, Diana, Yap, Fairuz, Teow, Teh, Ling, Elaine, Khoo, Teo \& Piong).

Caring, calmness and carefulness are the characteristics that men lack in general (Yen, Lee, Yap, Rawrays Co., Ling, Khoo, Teo \& Piong). The other characteristics that women own are more circumspect, optimistic, gentle, attractiveness, courageous, higher motivation, soft spoken, observant and wise (Yen, Lee, Yap, Rawrays Co., Zainorin, Teh, Ling, Khoo \& Teo). Besides, women are good in management compare with men and more focussed on marketing (Fairuz, Zainorin). These are the advantages that women posessed.

For men, they were more aggressive in their performance (Addy). Men made decisions in a shorter span of time compared to women (Poziyah, Teo \& Khoo). Men were more willing to share their ideas, abilities to communicate, had more momentum, has better risk management skills, highly motivated, had more strength to work, and even more capital (Teh, Rawrays Co., Diana, Yap \& Lee) Besides this, men always had more independence and were willing to leave home to achieve their business goals (Zainorin). However, according to a few respondents, indicated that female and male should have similar abilities and characteristic of an entrepreneur (Elaine, Teow, Eddie \& Kue Lan).

\section{RECOMMENDATION}

There are several recommendations that would be useful to promote entrepreneurship especially for female entrepreneurs. Apparently, appropriate government policies can have a huge impact on business growth, especially towards those who are still in their early stage of starting up their business. Having capital easily available for them would prove to be the first step towards a positive reinforcement to entrepreneurs especially towards female entrepreneur. Government should also release more schemes to aid entrepreneur during their early stage of setting up a business. Besides that, Malaysian government should develop proper tax and regulatory environment to further extended help towards entrepreneurs to attract more people into entrepreneurship. Education during primary and secondary school periods were proven to be an important phase to promote entrepreneur mind-set to the future breadwinners. Educator should always discover students' creativity, enhance them and teach them the value of becoming an entrepreneur.

\section{LIMITATION}

The information gathered is insufficient to generalize other countries' entrepreneurship condition which varies due to different culture and background. Therefore the results obtained would only outline the general characteristic and traits of entrepreneur in Malaysia but not of other countries. Also, the interviewees were selected based on convenience, sampling i.e. within the few states in Malaysia. This study was based on previous researches papers which were dated 4 to 15 years ago. Thus, it might not be as accurate reflection, because the economy is constantly changing and new initiatives are being implemented by the Malaysians Governments in relation to development of new entrepreneurs.

\section{CONCLUSION}

In conclusion, this research shows that both men and women can be as active entrepreneurs, and they share many common characteristics as well as some differences. Throughout this research, finding showed that there are six main elements that would significantly affect gender differences in entrepreneurship. Those elements are Characteristic differences, Family background, Social background, Government policy, Education and lastly Capability. Poor women in particular benefit from microfinance services. Such women, often the most disadvantaged group in a society, tend to be good credit risks. Increasing women's access to microfinance have wide-ranging benefits, not just for their well-being but also for the welfare of their families, the communities in which they live and for society at large. 
Complementing the communications campaign by a six month training program for a select group of lowincome women to equip them with the necessary tools to enhance their business skills and upscale their enterprises. Characteristic differences shown between both sexes are the first element; these can be seen in-terms of confidence level, independence level and also risk adverse level and lastly physical differences between them. Strong research backup claimed that the differences in brains and hormones are the cause of characteristic differences. The second element, family background is one of the most debated elements in entrepreneurship gender gap. Physical and mental family support are equally essential to entrepreneurs. Family's financial condition, marital status and also kids are few of the main focus in the family background element. The third element would be social background, social perception towards gender and also their bias and discrimination act would certainly differential a male and female entrepreneurs, female entrepreneurs are often discriminated and are often seen as inferior than male entrepreneurs, even in the $21^{\text {st }}$ century, there are still slight discrimination arise in different angles and perspectives although not significant but would proof to be a hurdle towards female entrepreneur's progression in this field. This is not an exception even it is in Malaysia, a developing country.

The fourth element, government policy does affect the gender differences of entrepreneurs in Malaysia. Schemes that help female in building their ventures have increased the number of female entrepreneurs in Malaysia. The fifth element is that education level between both genders in Malaysia has the equal rights to gain education. However, the needs of female to pursue education are much more significant than male so that they will be respected in the entrepreneurship field. Finally, capability wise, both female and male have their pros and cons, female are tend to be more influenced by relation ties and would foster strong ties with their workers and partners and would form social ties with their clients and dealers as well.

\section{AUTHOR INFORMATION}

Kogilah Narayanasamy is a Senior Lecturer in Faculty of Business \& Law. She holds a Master degree in Business Administration (IT Management). Her research area is primarily on E-commerce, Psychology and knowledge Management. Some of her recent conference presentations includes: A critical study of media profiling on society's social problem at the World Academy of Science Engineering and Technology Paris France 2011 and Phishing: A web server security scamming in e-commerce systems at Academy of Global Business Advancement (AGBA) Fourth World Congress. Some of her notable journal publications are: "The adoption and concerns of e-finance in Malaysia", Electronic Commerce Research, "Knowledge sharing in virtual teams in Malaysia", Journal of Information and Knowledge Management and E-Business, "Security and Trust: Problems and Prospects", Journal of E-Business. E-mail: kogilah@mmu.edu.my

Dr DevinagaRasiah*is a Senior lecturer with the Faculty of Business \& Law. Her MBA is from University of Wales, UK. Her PhD is in the area of Banking \& Finance. Her research interests are in Corporate Finance, commercial and investment banking. Apart from these, she is also interested in topics relating to internal controls, Automated Teller Machine services and self service technologies at commercial banks. E-mail: devinaga.rasiah@mmu.edu.my

C J Jacobs (CJ Gletus Matthews C N Jacobs) is a member of Malaysian intellectual Property Association (MIPA) and Member of International Sociology of Sports Association. He holds a Masters Degree in Law from Anglia (Ruskin) University United Kingdom specialising in International Sports Law. He worked for many years in the corporate sector before embarking in the academic field. Currently he is a Senior Lecturer in Law at the Multimedia University Melaka campus Malaysia .His current research interests in Sports Law, Political Philosophy and Cyber law.

Some of his notable publications are as follows: "The theory of Social Contract shaping today's' society." International Journal of Social Research Turkey Vol. 3/10 2010, "Human Rights in sports in a globalising world" Journal Ilmiah International 2010, "The effect of Basel Committee on banking system for combating money laundering." Malayan Law Journal 2011, and "The legal regulation in sports and the Malaysian impasse." Malayan Law Journal 2011 


\section{REFERENCES}

1. Aldrich, H., Elam, A., \& Reese, P. (1997). Strong ties, weak ties and strangers; do women differ from men in their use of networking to obtain assistance? In S. Birley \& I. MacMillan (Eds), Entrepreneurship in a global context. London: Routledge.

2. Bird, B. \& Brush, C. (2002). A gendered perspective on organization creation. Entrepreneurship, Theory and Practice, 26(3), 41-65.

3. Boohene, R., Kotey, B. and Folker, C.A. (2005), " Explaining gender differences in performance among small and medium enterprise owners in Ghana", Proceedings of the International Council of Small Business 50th Annual Conference, Washington, DC, June.

4. Boohene, R., Sheridan, A., \& Kotey, B. (2008). Gender, personal values, strategies and small business performance: A Ghanaian case study. Equal Opportunities International, 27(3), 237257.

5. Bortey, C.A. and Dodoo, F. (n.d.), “Adolescent attitudes regarding gender roles in Ghana”, Available (19 January 2005).

6. $\quad$ Brindley, C. (2005). Barriers to women achieving their entrepreneurial potential." International Journal of Entrepreneurial Behaviour \& Research 11(2): 144-161.

7. BusinessDictionary.com. (2009). Interview. Retrieved 3 May, 2009, URL : http://www.businessdictionary.com/definition/interview.html

8. Istanbul (2004). Promoting Entrepreneurship and Innovative SMEs In a Global Economy. $2^{\text {nd }}$ OECD conference of Ministers Responsible For Small And Medium-Sized Enterprises (SMEs).

9. Justo \& Coduras(2006) Entrepreneurs' Perceptions of Success: Examining Differences Across Gender and Family Status

10. Klenke, K. (2003). Gender influences in decision making processes in top management teams. Management Decision, 41(10), 1024-1034.

11. Levent, T. B., E. Masurel, et al. (2003). "Gender Differences in Ethnic Entrepreneurship." European Regional Science Association (ERSA).

12. Malach-Pines, A. and D. Schwartz (2007). "Now you see them, now you don't: gender differences in entrepreneurship." Journal of Managerial Psychology 23(7): 811-832.

13. Marlow, S., \& Patton, D. (2005). All Credit to Men? Entrepreneurship, Finance, and Gender. Entrepreneurships Theory and Practice, 717-735.

14. McClelland, E., J. Swail, et al. (2005). Following the pathway of female entrepreneurs. International Journal of Entrepreneurial Behaviour \& Research 11(2): 84-107.

15. Mueller, S. L. (2007). Gender-role orientation as a determinant of entreprenuer self-efficacy. Journal of Developmental Entrepreneurship, Vol. 13(No. 1).

16. Nikoi, G. (1993), Gender and Development, Buck Press Ltd, Accra.

17. Parker, S. C. (2004). The economics of self-employment and entrepreneurship.

18. Purdy, L. (2005). Women's reproductive autonomy: medicalisation and beyond. Journal of Medical Ethics 32: 287-291.

19. Rajan, S., \& Venkat R, K. (2002). Impact of gender on influence, power and authoritarianism. Women in Management Review, 17(7), 197-206.

20. Sekaran, Uma (2003), "Research Methods for Business", $4^{\text {th }}$ Edition, John Wiley \& Sons, Inc., New York.

21. Shane, S. and S. Venkataraman. 2000. "The Promise of Entrepreneurship as a Field of Research," Academy of Management Review 25, no. 1: 217-26.

22. Small Business Service (SBS) Small and Medium-Sized Enterprise (SME) Statistics for the UK, 2005

23. Spinder Dhaliwal \& Peter Kangi (2006) "Asians in the UK: gender, generation and enterprise," Equal opportunities International, Vol. 25 No. 2, pp. 92-108.

24. Wagner, J. (2007). What a Difference a Y makes-Female and Male Nascent Entrepreneurs in Germany. Small Business Economics, 28, 1-21.

25. Wiebe and Frank. An "Entrepreneur Career Selection and Gender: A Socialization Approach".

26. Woldie, A. and A. Adersua (2004). "Female entrepreneurs in a transitional economy." International Journal of Social Economics 31(1/2): 78-93. 


\section{NOTES}

